\title{
NOTAS BREVES.
}

- Nuestro consocio, Dr. A. J. Sharp ha descrito una variedad de Ilex vomitoria, a la que ha denominado I. vomitorio chiapensis (Bot. Mus. Leafl. Harvard Univ. 14. 4 1950).

-La Sociedad Botánica de México ha colocado una lápida en la tumba de C. A. Purpus; distinguido botánico que residió muchos años en nuestro país, donde formó importantes colecciones. Purpus nació en Darmstadt el 26 de febrero de 1851 y murió én El Mirador, Ver. el 17 - de enero de 1941.

El Sr. Norberto Grohmann colaboró gencrosamente en la colocación cle la lápida.

- Ha aparecido una nueva revista denominada La Ceiba, publicada por la Escuela Agrícola Panamericana, de Tegucigalpa, Honduras. Entre los bien seleccionados artículos contenidos en el primer número sobresale el del Dr. E. D. Merxill, intitulado "Observaciones acerca de las plantas cultivadas, con referencia a ciertos problemas americanos".

-El Presidente de nuestra Sociedad, Dr. Ladislao Paray, ha formado un interesante álbum de acuarelas, representando diversas plantas mexicanas ornamentales.

- Se ha publicado el Vol. 20 de los Anales del Instituto de Biología, en el cual aparecen los siguientes artículos sobre Botánica.

"Nota sobre el Pinus Cooperi" por' C. E. Blanco.

"Gutiferas nuevas de Colombia" por J. Cuatrecasas.

"On the nature of trunk bark production by young Cinchonae" por R. F. Dawson.

"Las Pseudotsugas le México" por Maximino Martínez.

"The recorded vernacular names of members of the Verbenaceae, Avicenniaceae and Symphoremaceae" por H. N. Moldenke. 
"Notas sobre la vegetación de la Sierra de Tepoztlán” por D. R. Cantú.

"Nueva variedad de Micoderma cerevisiae" por M R. Ornoz.

-El Prof. Maximino Martínez está preparando una nueva edición del Catálogo de nombres vulgares y crentílicos de plantas mexicanas. -Nuestro consocio, Ing. Gustavo Aguirre Benavides exhibió en una de nuestras reuniones una colección de vistas a colores que tomó en San Luis Potosí y Querétaro. Llamaron la atención sobre todo las que representan la Garcia mutans.

- La distinguida cactóloga Helia Bravo ha reanudado sus trabajos de investigación en el Instituto de Biolegía.

-El Dr. Manuel Maldonado K. sustentó en una do las juntas de nuestra Sociedad una conferencia sobre La Paleobotánica en México. -El 11 de marzo falleció nuestro Socio Honorario el eminente biólogo Dr. Isaac Ochoterena. 